\title{
Effects of common daisy (Bellis perennis L.) aqueous extracts on anxiety-like behaviour and spatial memory performance in Wistar albino rats
}

\author{
F. Pehlivan Karakaş ${ }^{1 \star}$, A. Karakaş ${ }^{1}$, H. Coşkun ${ }^{2}$ and A. Uçar Turker ${ }^{1}$ \\ ${ }^{1}$ Department of Biology, Faculty of Arts and Sciences, Abant Izzet Baysal University, Bolu 14280, Turkey. \\ ${ }^{2}$ Department of Psychology, Faculty of Arts and Sciences, Abant Izzet Baysal University, Bolu 14280, Turkey.
}

Accepted 17 June, 2011

The effects of aqueous extract of flowers from Bellis perennis on anxiety-like behavior and memory in Wistar rats were tested. Vehicle 20 and $60 \mathrm{mg} \mathrm{kg}^{-1} B$. perennis groups were performed and the animals were tested by open field and elevated plus maze tests for anxiety-like behaviour and Morris water maze test for spatial memory. In the open field, the high dose of $B$. perennis administrated rats spent more time at the center, showed less mobility and velocity. In the elevated plus maze, the high dose of $B$. perennis administrated rats spent more time in the open arms, spent less time in the closed arms, were less mobile, were slower and rotated less frequently. In the Morris water maze, the high dose of $B$. perennis administrated rats spent more of the time to find the platform. In conclusion, $B$. perennis may produce biphasic effects on both anxiety-like behaviour and learning performance of the rats.

Key words: Bellis perennis, common daisy, anxiety, sedative, spatial memory.

\section{INTRODUCTION}

Bellis perennis L. (common daisy), a herbaceous perennial plant of meadows, lawns and other grassy areas, is a member of the Asteraceae family. It is native to western, central and northern Europe, but is commonly found as an invasive plant in North America (Tutin et al., 1976; Panda, 2004). Common daisy has been used as a diuretic, antispasmodic, anti-inflammatory, astringent, expectorant, antipyretic, vulnerary, ophthalmic and homeostatic in traditional medicine (Grieve, 1982; Bown, 1995; Baytop, 1999; Duke et al., 2002). The main constituents are triterpenoid saponins (Hiller et al., 1988; Schopke et al., 1990, 1991, 1992; Li et al., 2005; Morikawa et al., 2008; Yoshikawa et al., 2008), flavonoids (Gudej and Nazaruk, 2001) and essential oils (Avato et al., 1997; Kavalcioglu et al., 2010). Antibacterial, antifungal, antioxidant (Desevedavy et al., 1989; Avato et al., 1997; Kavalcioglu et al., 2010), antihyperlipidemic (Morikawa et al., 2008, 2010a), postpartum antihemorrhagic (Oberbaum et al., 2005), pancreatic lipase inhibitor

\footnotetext{
${ }^{*}$ Corresponding author. E-mail: pehlivan_f@ibu.edu.tr. Tel: +90374- 254 1000. Fax: +90-374- 2534642.
}

(Morikawa et al., 2010b) and cytotoxic activities against $\mathrm{HL}-60$ human promyelocytic leukemia cells ( $\mathrm{Li}$ et al., $2005)$ of $B$. perennis have also been shown. Anxiety is a common experience in daily life which causes substantial suffering in the general population. The data from Western Countries report the prevalence estimates as high as 10 to $15 \%$ of the population (Regional Health Forum). This high percentage of the prevalence of the anxiety disorder in general population is elevating the importance of the results of the animal experiments especially for the drug treatments. $B$. perennis may be one of the plausible treatments for reducing anxiety. As best as is known, there has been no reported research that examines the plausible anxiolytic effects of $B$. perennis on anxiety in the literature. Also, it would be interesting to see whether or not its effects on anxiety changes with gender.

For instance, juveniles may become more anxious than adults for various reasons (for example, differences in olfactory or visual sensations and searching behaviors for environmental cues) and thereby are more sensitive to the effects of either high or low doses of $B$. perennis than adults. Such plausible outcome requires an experimental research paradigm that investigates both dose treatment 
(for example, high or low doses) and generation in a single research paradigm in which has not been found in the relevant literature so far. In addition to this, the fact that $B$. perennis may have important effects on learning performance has been disregarded in the literature. Given the consideration mentioned earlier, if $B$. perennis has an anxiolotic effect, it should enhance learning performance. If not or if it has an anesthetic effect, then it can decrease spatial learning performance. These possibilities are among interesting research concerns that need to be answered. Given the considerations mentioned earlier, the present study was conducted to investigate the effects of $B$. perennis injection on the anxiety like behaviors via open field (Benabid et al., 2008) and elevated plus maze (Dawson and Tricklebank, 1995) and spatial memory performance of the rats via the Morris water maze (Hooge and De Deyn, 2001). This is because it is still not known whether $B$. perennis extracts are effective or not on anxiety like behaviors and spatial memory.

\section{MATERIALS AND METHODS}

\section{Plant material}

Common daisy (B. perennis L.) flowers and pedicels were collected from Abant Izzet Baysal University Campus, Bolu, Turkey in May 2009. Identification of the species was made by using "Flora of Turkey and the East Aegean Islands" (Davis, 1975) and voucher specimen (collection number AUT-1909) was deposited at the Abant Izzet Baysal University (AIBU) Herbarium, Bolu, Turkey.

\section{Preparation of the common daisy extracts}

Collected common daisy flowers and pedicels were dried in oven at $40^{\circ} \mathrm{C}$ and then ground into a powder. For aqueous extraction, $20 \mathrm{~g}$ from powdered plant sample were extracted with $200 \mathrm{ml}$ water at $80^{\circ} \mathrm{C}$ in a water bath for $12 \mathrm{~h}$ and then filtered. Frozen filtrate was lyophilized by using freeze-dryer at $-65^{\circ} \mathrm{C}$. Residue was dissolved in serum physiologic $(0.9 \% \mathrm{NaCl})$ to produce a final concentration of $100 \mathrm{mg} \mathrm{ml}^{-1}$. The yield of extract (w/w) was $15 \%$.

\section{Animal care}

Adult male Wistar rats (200 to $250 \mathrm{~g}$ ) were obtained from our laboratory colony maintained at the Abant Izzet Baysal University (AIBU). They were exposed from birth to $12 \mathrm{~L}$ (12 h of light, $12 \mathrm{~h}$ of darkness, lights off at $1800 \mathrm{~h}$ ). Animals were maintained in plastic cages $(16 \times 31 \times 42 \mathrm{~cm})$ with pine shavings used as bedding. Food pellets and tap water were accessible ad libitum. The procedures in this study were carried out in accordance with the Animal Scientific procedure and approved by the Institutional Animal care and Use Committee. All lighting was provided by cool-white fluorescent tubes controlled by automatic programmable timers. Ambient temperatures in the animal facilities were held constant at $22 \pm 2^{\circ} \mathrm{C}$ in air-ventilated rooms.

\section{Administration of the extract}

In the present study, adult (n:18) and juvenile (n:18) and totally the thirty six male rats were used and were randomly divided into three groups as vehicle, $20 \mathrm{mg} \mathrm{kg}^{-1}$ B. perennis aqueous extract injection (low dose) and $60 \mathrm{mg} \mathrm{kg}^{-1}$ B. perennis aqueous extract injection (high dose). Intraperitoneal injections were applied everyday at 13:00 $\mathrm{h}$ starting from the 1st day to the end of the experiment. In vehicle group, animals were injected with the same amount of the saline to obtain the same stress conditions with the experiments groups. Anxiety-like behaviour and spatial memory of Wistar rats were measured at 15:00 $\mathrm{h}$ by a means of open field, elevated plus maze and Morris water maze test, respectively.

\section{Open field}

Open-field test is taken place in an $80 \times 80 \mathrm{~cm}$ arena with $40 \mathrm{~cm}$ high walls. The open field has been the most widely used test in animal psychology. In this test, an animal (usually a rodent) is introduced into a plain and illuminated arena and its behavior is commonly regarded as a fundamental index of general behavior. In this experiment a video camera (Gkb CC-28905S, Commat LTD.ŞTi. Ankara/Turkey) was mounted above the arena, recording behavior into the Ethovision videotracking system (Noldus Ethovision, Version 6, Netherland; Commat LTD.ŞTi. Ankara/Turkey) that provided a variety of behavioral measures including distance, time in the edge, time in the center, frequency in the edge, frequency in the center, mobility and velocity among the different areas of the arena. All animals were then returned to the breeding and exhibition colonies.

\section{Elevated plus maze}

The elevated plus maze consisted of the two open and two closed $10 \mathrm{~cm}$ wide arms in a plus-sign configuration of $55 \mathrm{~cm}$ off the floor. The closed arms were enclosed by $41 \mathrm{~cm}$ tall black Plexiglas. All arms were covered with contact paper to prevent the animals from sliding off, and all surfaces were wiped with $70 \%$ alcohol between animals. Each animal was released into one of the closed arms and allowed to move freely on the maze for a 5-min testing period that was videotaped from above the maze. Animals that fell off the maze into compartments below were placed back on the maze for the remainder of the testing period. An observer uninformed about experimental conditions scored the videotapes with The Observer Software (EthoVision XT) (Noldus Ethovision, Version 6, Netherland; Commat LTD.ŞTi. Ankara/Turkey) for distance, duration in the open arm, frequency in the open arm, duration in the closed arms, frequency in the closed arms, mobility and velocity. Animals were considered to have entered an arm when all four paws crossed onto the arm.

\section{Morris water maze}

For the spatial memory, the performances of the rats in the Morris water maze were evaluated. The experiments were carried out in a circular, galvanized steel maze $(1.5 \mathrm{~m}$ in diameter and $60 \mathrm{~cm}$ in depth), which was filled with $40 \mathrm{~cm}$ deep water kept at $28^{\circ} \mathrm{C}$ and rendered opaque by the addition of a non-toxic, water soluble dye. The maze was located in a large quiet test room, surrounded by many visual cues external to the maze (for example the experimenter, ceiling lights, rack, pictures, etc.), which were visible from within the pool and could be used by the rats for spatial orientation. Locations of the cues were unchanged throughout the period of testing. A video camera fixed to the ceiling over the center of the maze was used for recording and monitoring movements of the animals. There were the four equally divided quadrants in the pool. In one of the quadrants, a platform $(1.0 \mathrm{~cm}$ below water surface, $10 \mathrm{~cm}$ in diameter) was submerged centrally and fixed in 
position which was kept constant throughout the acquisition trials. The rats performed the four trials per day for the four consecutive days (16 trials). In the swimming trials, each individual rat was released gently into the water at a chosen quadrant except for the one that contained the hidden platform for facing an extra maze cue. The rat swam and learned how to find the hidden platform. After reaching, the rat was allowed to stay on the platform for $15 \mathrm{~s}$ and was then taken back into the cage. During the inter-trial intervals, animals were kept in a dry home cage for $60 \mathrm{~s}$.

The video camera recordings were obtained on the fifth day of the experiment. The rat had to swim until it climbed onto the platform submerged underneath the water. The escape platform was kept in the same position relative to the distal cues. The time to reach the platform, total distance travelled, time passed in the correct quadrant, entrance frequency to the correct quadrant and immobility were measured as the indexes of the spatial memory. In this experiment a video camera (Gkb CC-28905S, Commat LTD.ŞTI. Ankara/Turkey) was mounted above the arena, recording behavior into the Ethovision videotracking system (Noldus Ethovision, Version 6, Netherland; Commat LTD.ŞTi. Ankara/Turkey) that provided a variety of behavioral measures including distance, time in the edge, time in the center, frequency in the edge, frequency in the center and immobility among the different areas of the arena. All animals were then returned to the breeding and exhibition colonies.

\section{Statistical analysis of the data}

Data were analyzed using SPSS (SPSS Statistical Software, SPSS Inc., Los Angeles, CA, USA, Ver. 15.0). Data were analyzed by 2 (generation: adult and juvenile) $X 3$ (treatments: vehicle, low dose and high dose of $B$. perennis) ANOVA analysis. Values were considered statistically significant at $p \leq 0.05$. Data are presented as means in the relevant paragraphs and illustrated as mean \pm SEM in Figures 1 to 3 after back transforming from ANOVA results. The Tukey test was used to compare significant mean differences in treatment condition.

\section{RESULTS}

\section{Open field measurements}

\section{Total distance travelled (TDT)}

The main effect of the treatment was significant on the total distance travelled in the open field, $(F(2,30)=$ 47.89, $\left.p=0.00001, \eta^{2}=0.76\right)$. Tukey test indicated that the subjects in high doses of $B$. perennis $(M=1065.94)$ travelled less distance than the subjects of those in control condition $(\mathrm{M}=2377.22)$ and low doses of $B$. perennis $(M=2334.66)$, with the last two being not significantly different from each other. The interaction effect was significant between generation and treatment $F(2,30)=6.66, p=0.004, \eta^{2}=0.31$. This interaction reflected the fact that the difference between the control condition ( $\mathrm{M}=2680.64)$ and high dose condition $(\mathrm{M}=$ 1034.64) was greater in juveniles than the difference between control condition $(\mathrm{M}=2073.81)$ and high dose condition ( $M=1097.25)$ in adults.

\section{Time spent at the edge of the open field (TSEO)}

The main effect of the generation was significant on the time spent at the edge of the open field, $(F(1,30)=$ 22.35, $\left.p=0.0001, \eta^{2}=0.43\right)$. Juveniles $(M=4.91)$ spent more time at the edge of the open field than adults $(M=$ 4.75). The interaction effect between the generation and the treatment was significant $(F(2,30)=3.91, p=0.03$, $\left.\eta^{2}=0.21\right)$. This interaction reflected the fact that adults in control condition $(M=4.86)$ spent more time at the edge of the open field than those in high dose condition $(\mathrm{M}=$ 4.66), but, this trend was not evident in juveniles.

\section{Time spent at the center of the open field (TSCO)}

The main effect of the generation was significant on the time spent at the center of the open field, $(F(1,30)=$ 22.35, $\left.p=0.0001, \eta^{2}=0.43\right)$. Adults $(M=0.25 \mathrm{~min})$ spent more time at the center of the open field than juveniles ( $M=0.09)$. The interaction effect between the generation and the treatment was also significant $(F(2$, $\left.30)=3.91, p=0.03, \eta^{2}=0.21\right)$. This interaction reflected the fact that adults in control condition $(M=0.15)$ spent less time at the center of the open field than those in high dose condition ( $M=0.34)$, but, this trend was not evident in juveniles.

\section{Entrance frequency to the edge of the open field (EFEO)}

The main effect of the treatment was significant on the entrance frequency to the edge of the open field, $(F(2$, 30) $\left.=8.64, p=0.001, \eta^{2}=0.37\right)$. The Tukey test indicated that the subjects in high dose condition $(\mathrm{M}=$ 2.50) were less frequently to enter the edge of the open field than those in the control condition $(M=6.17)$ and those in the low dose condition $(M=6.17)$, with the last two being not significantly from each other. This finding shows that high dose of $B$. perennis decrease the total entrance frequency to the edge of the open field. This also indicates that such dose decreases the anxiety level of the rats.

\section{Entrance frequency to the center of the open field (EFCO)}

The main effect of the treatment was significant on the entrance frequency to the center of the open field, $(F(2$, 30) $\left.=8.21, p=0.001, \eta^{2}=0.35\right)$. The Tukey test indicated that the subjects in high dose condition ( $\mathrm{M}=$ 1.67) entered less frequently to the center of the open field than those in the control condition $(M=5.17)$ and 
(A)

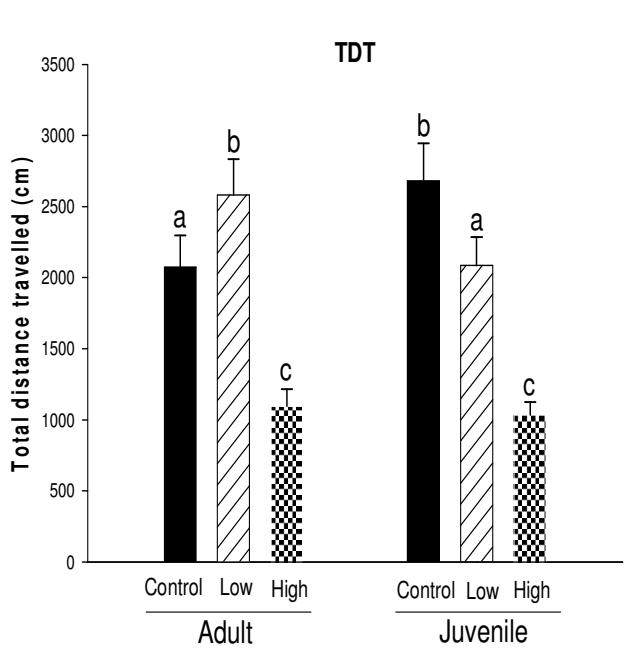

(E)

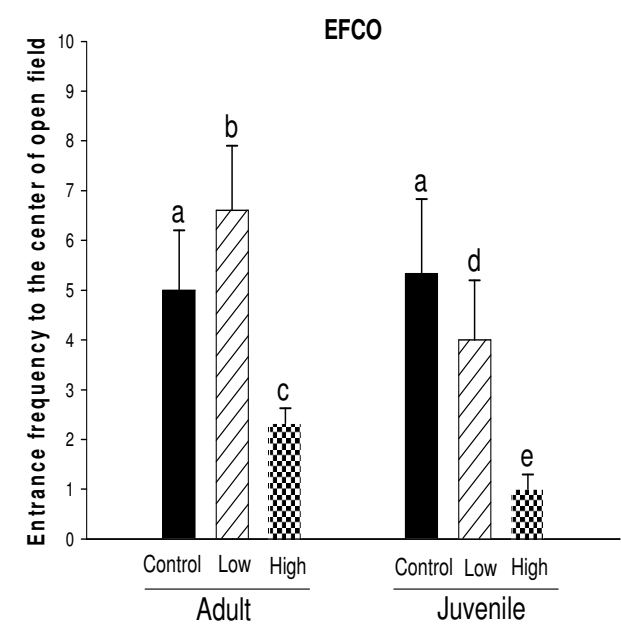

(B)

(F)

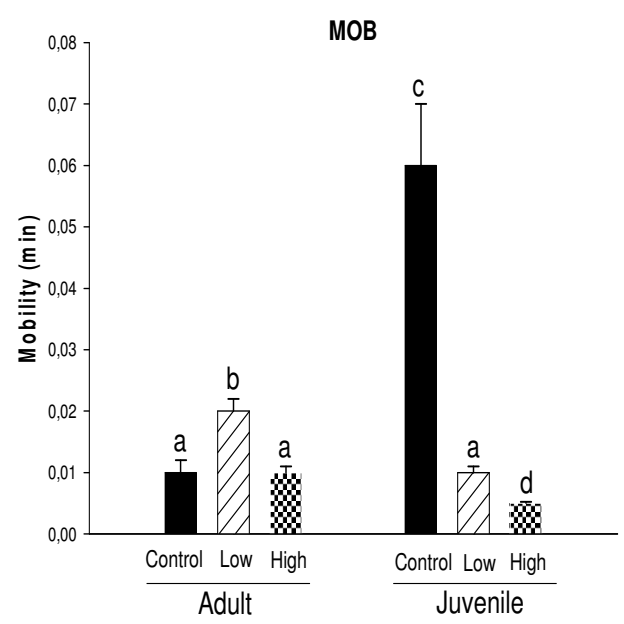

TSEO

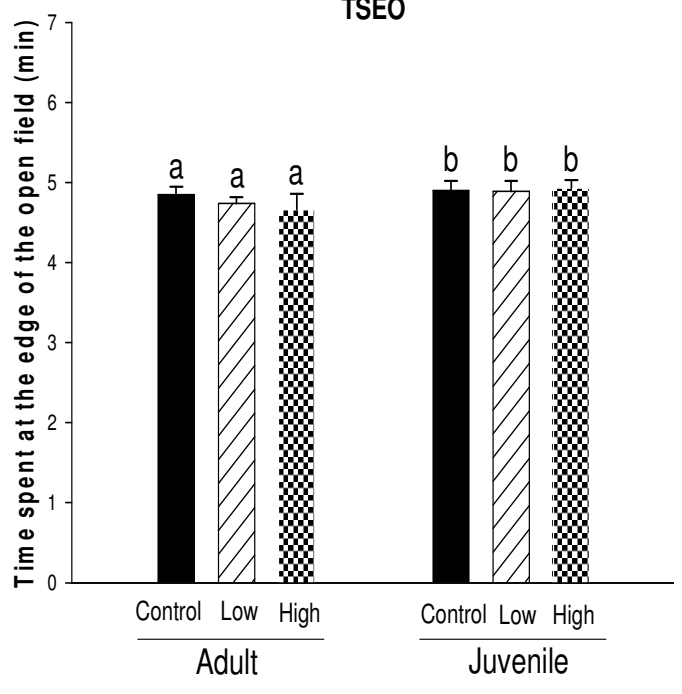

(C)

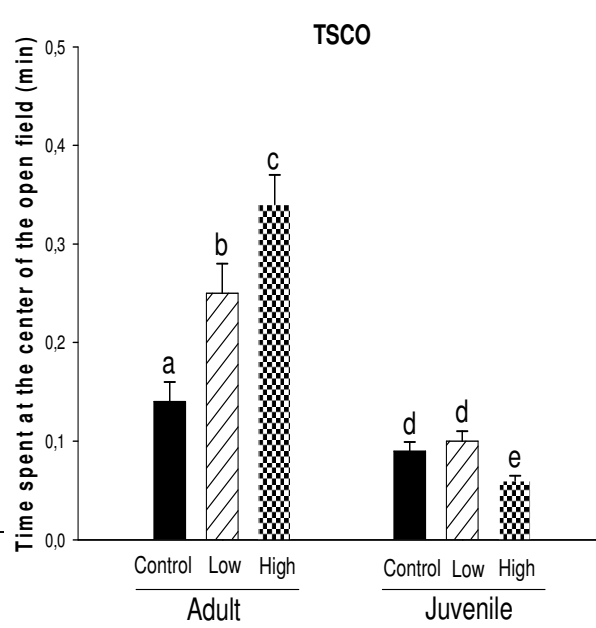

(G)

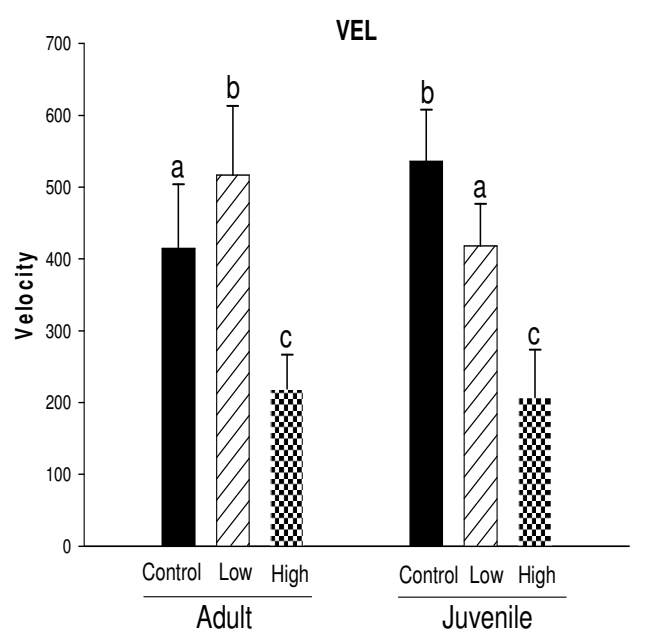

(D)

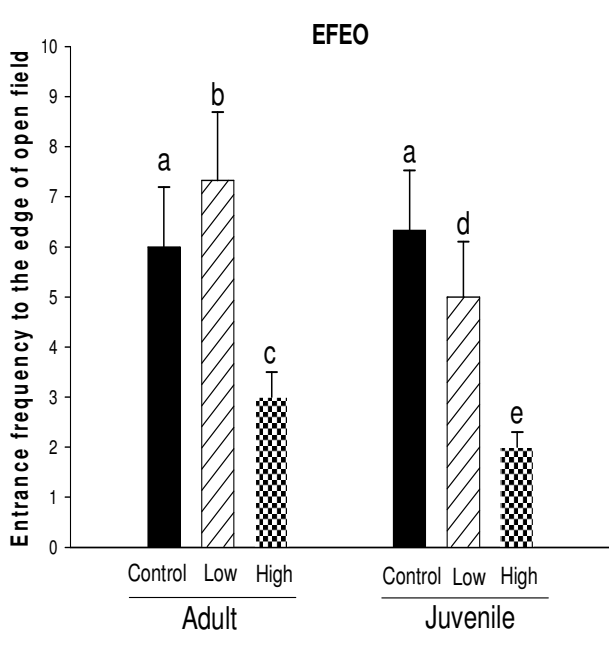

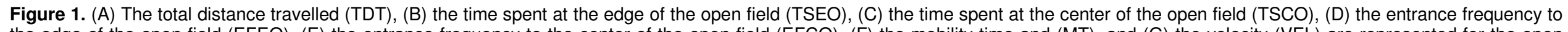

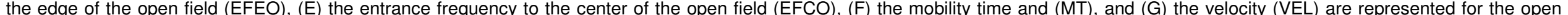

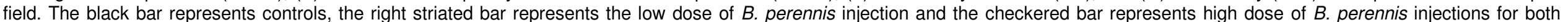
adults and juveniles. Data are presented as means ( \pm S.E.M.). Different letters indicate the statistically different groups. 
(A)

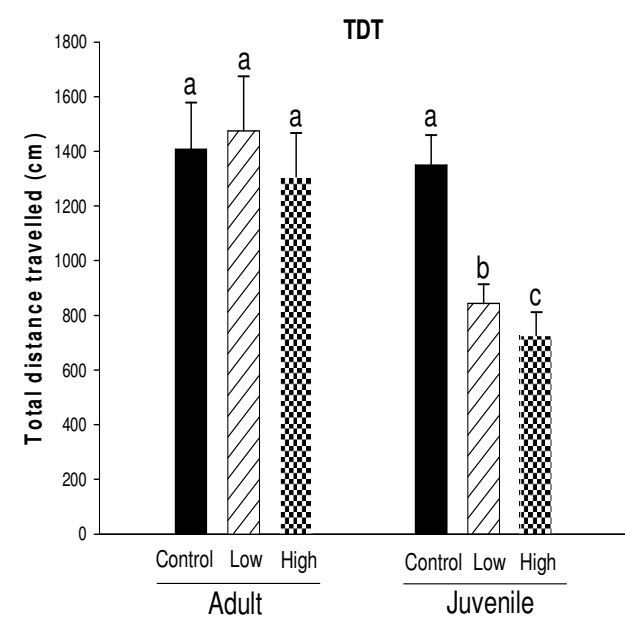

(E)

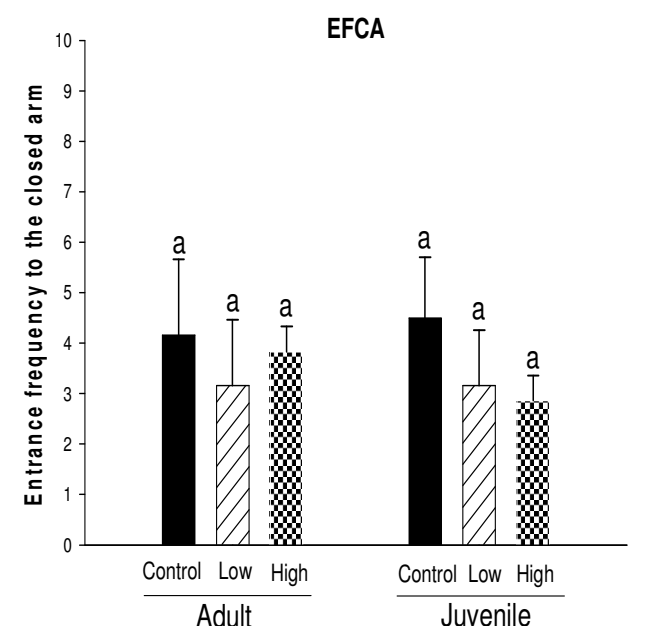

(B)

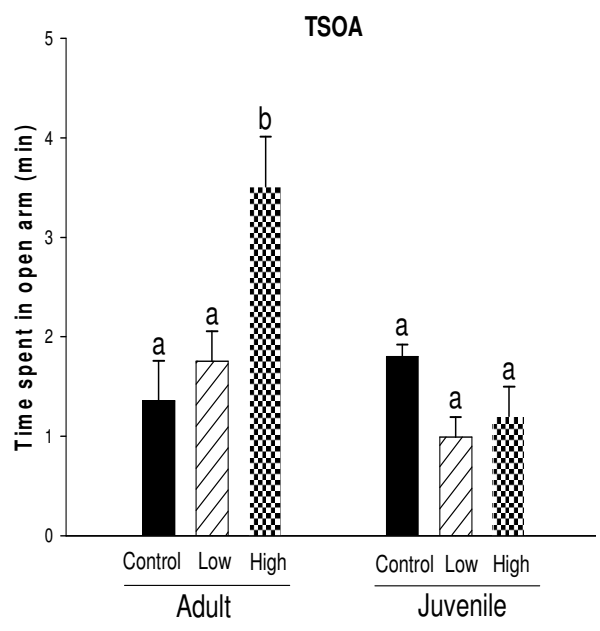

(F)

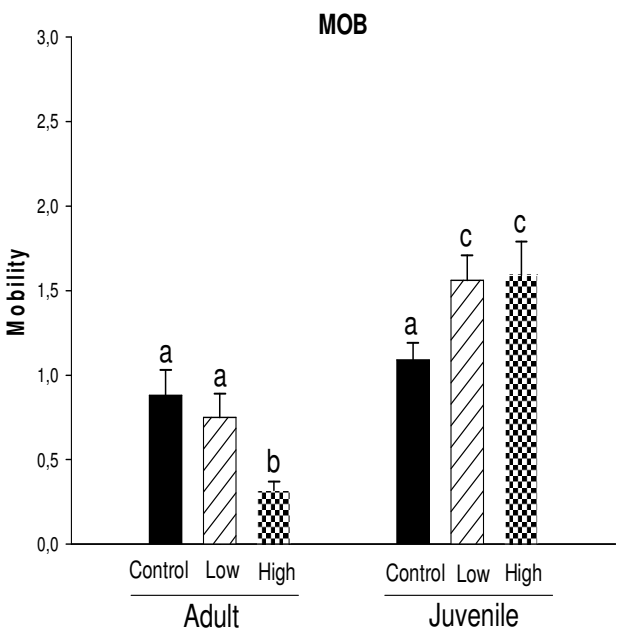

(C)

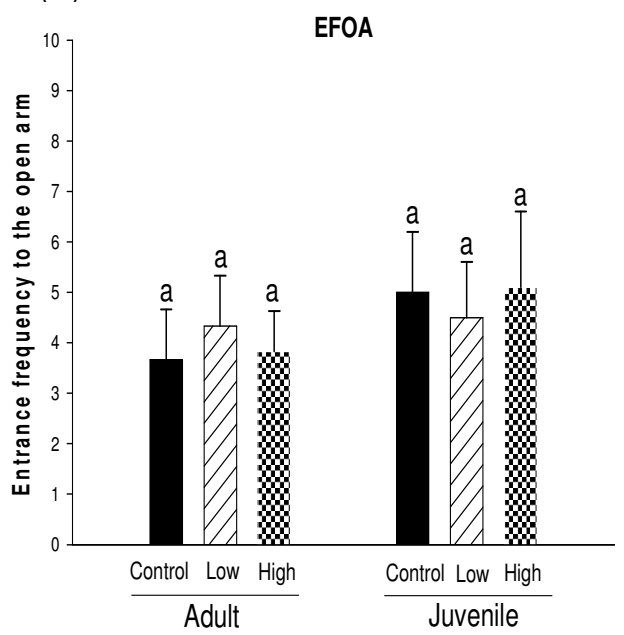

(G)

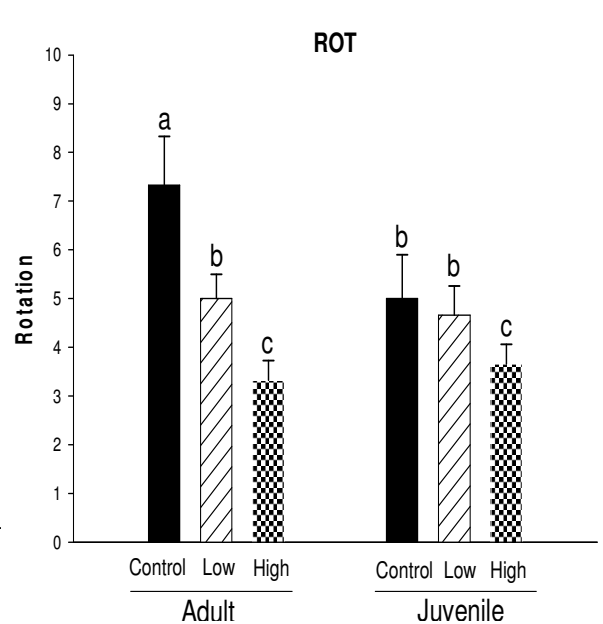

(D)

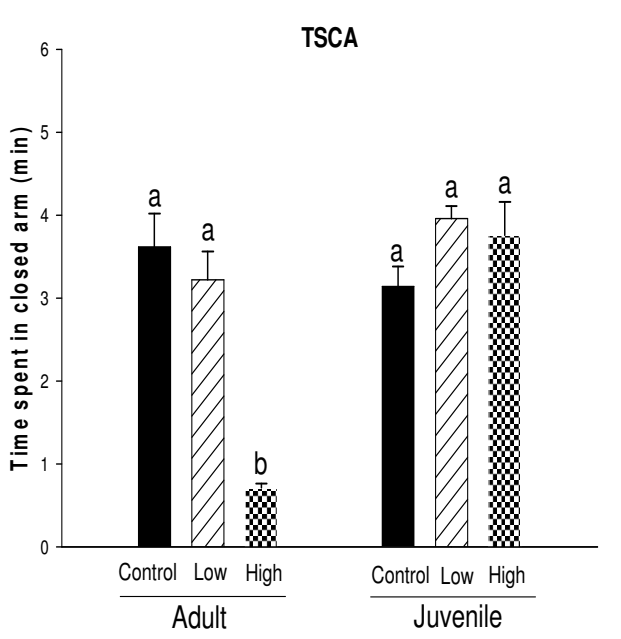

(H)

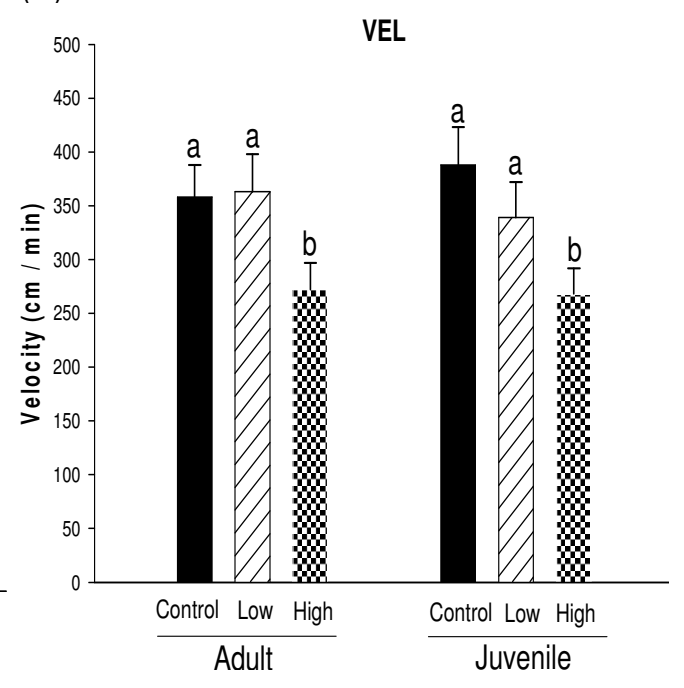

Figure 2. (A) The total distance travelled (TDT), (B) the time spent in open arms (TSOA) (C), the entrance frequency to the open arms (EFOA), (D) the time spent in closed arms (TSCA), (E) the entrance frequency to the closed arms (EFCA), (F) the mobility time (MT), (G) the rotation, and (H) the velocity (VEL) are represented for the elevated plus maze. The black bar represents controls, the right striated bar represents the low dose of $B$. perennis injection and the checkered bar represents high dose of $B$. perennis injections for both adults and juveniles. Data are presented as means $( \pm$ S.E.M.). Different letters indicate the statistically different groups. 
(A)

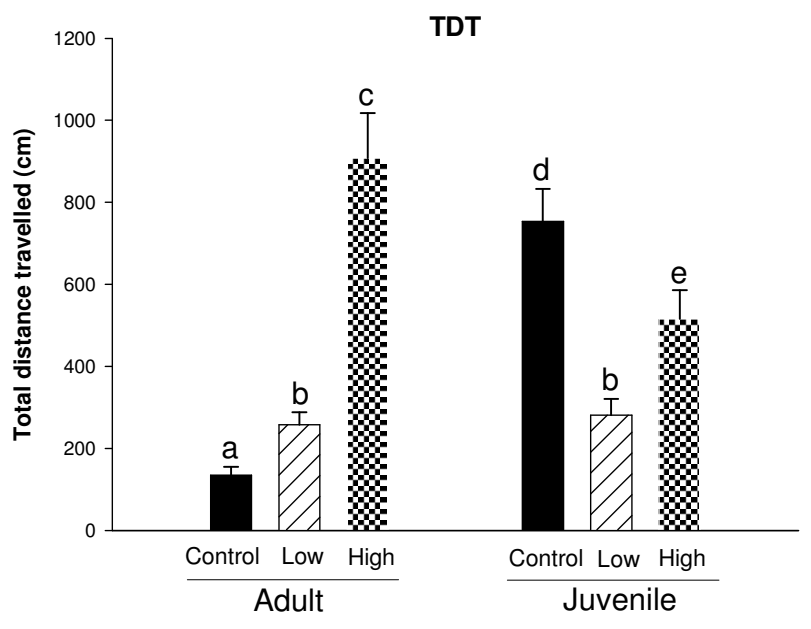

(C)

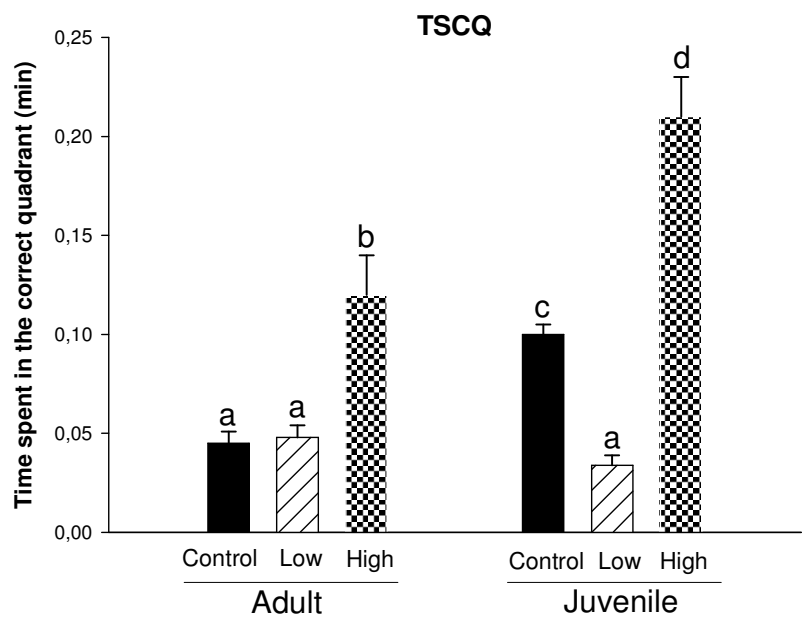

$(\mathrm{E})$

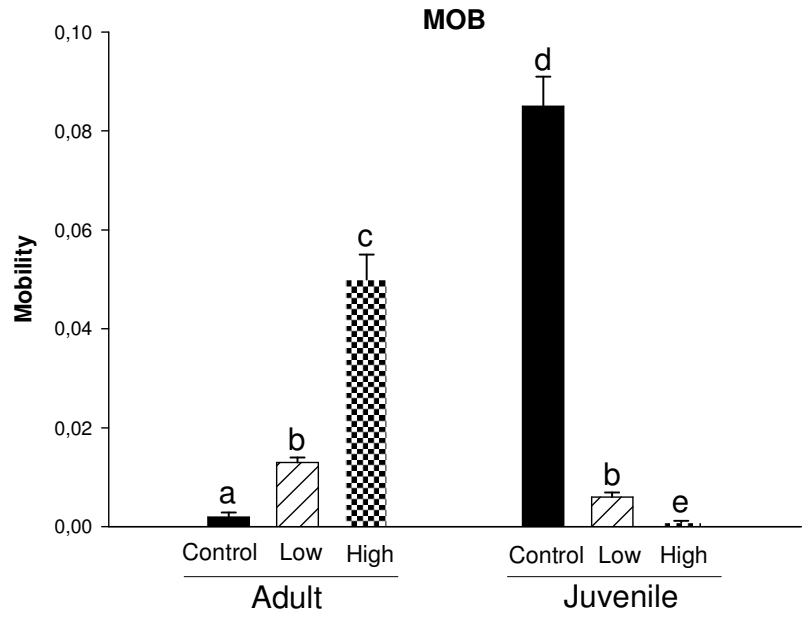

(B)

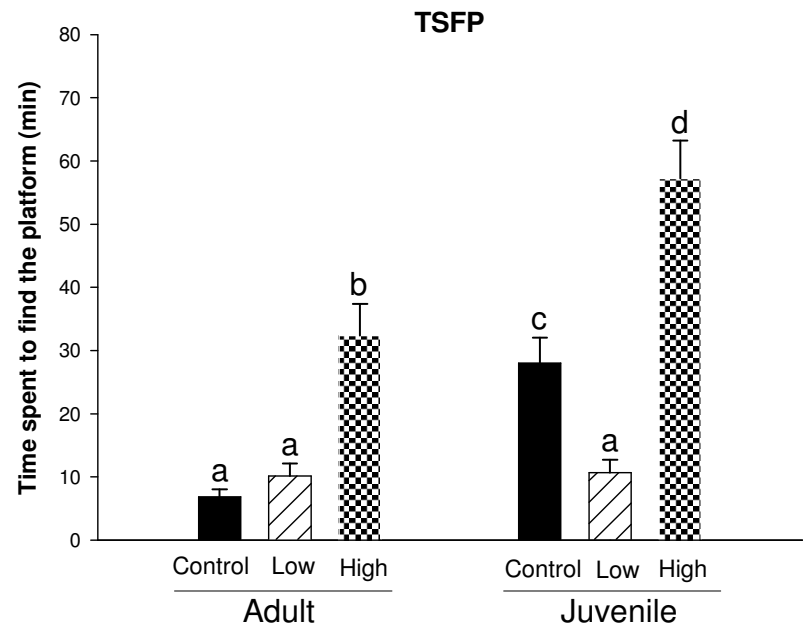

(D)

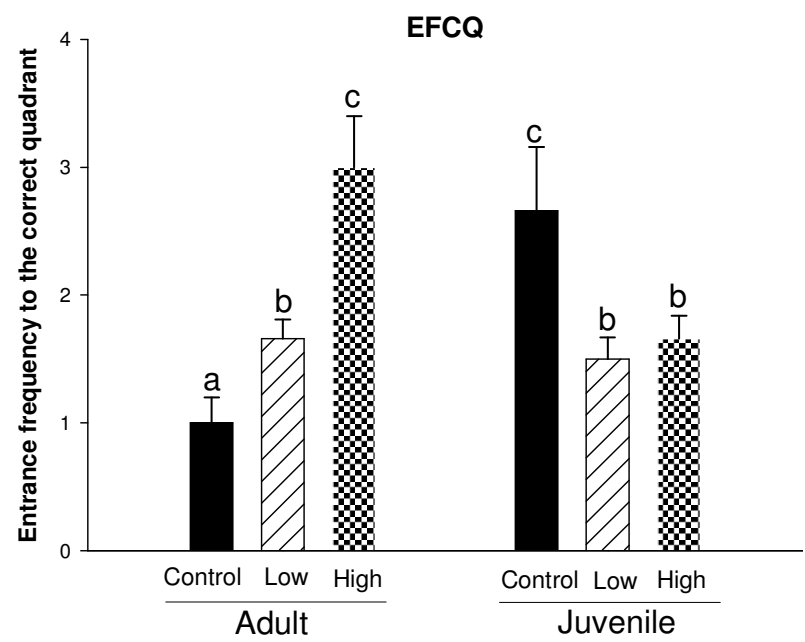

$(\mathrm{F})$

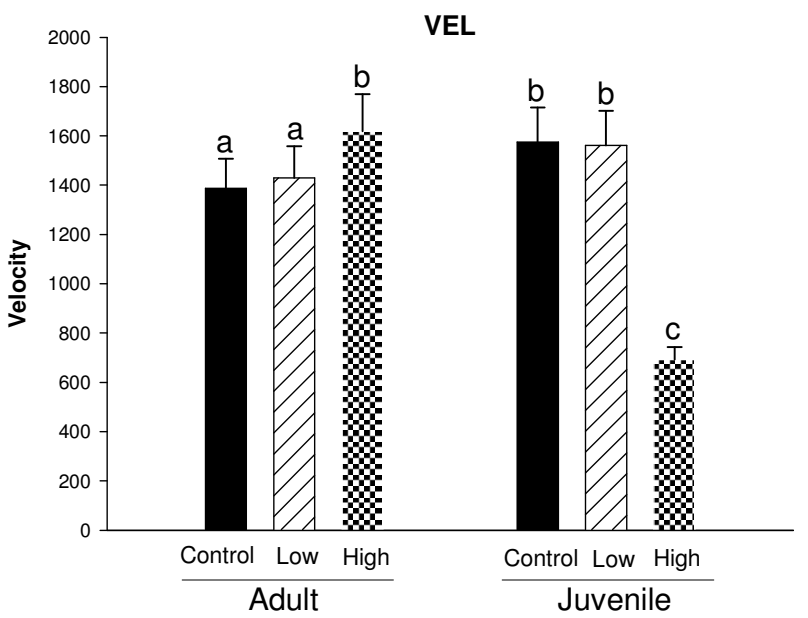

Figure 3. (A) The total distance travelled (TDT), (B) the time spent to find the platform (TSFP), (C) the time spent in the correct quadrant (TSCQ), (D) the entrance frequency to the correct quadrant (EFCQ), (E) the mobility time and (MT), and (F) the velocity (VEL) are represented for the Morris water maze. The black bar represents controls, the right striated bar represents the low dose of $B$. perennis injection and the checkered bar represents high dose of $B$. perennis injections for both adults and juveniles. Data are presented as means ( \pm S.E.M.). Different letters indicate the statistically different groups. 
those in the low dose condition $(M=5.33)$, with the last two being not significantly different from each other. These finding shows that high dose of $B$. perennis decreases the total entrance frequency to the edge of the open field. This also indicates that such dose decreases the anxiety level of the rats.

\section{Mobility (MOB)}

The main effect of the treatment was significant on the mobility, $F(2,30)=78.66, p=0.0001, \eta^{2}=0.84$. The Tukey test indicated that the subjects in the control condition ( $M=0.03$ ) were more mobile than those in low $(\mathrm{M}=0.007)$ and high doses of $B$. perennis $(\mathrm{M}=0.00)$, with the last two being significantly different from each other. The main effect of the generation was also significant on the mobility, $F(1,30)=130.01, p=$ $0.00001, \eta^{2}=0.81$. Juveniles $(M=0.03)$ were more mobile than adults $(M=0.00)$. In addition, the interaction effect between generation and treatment was significant, $\left(F(2,30)=79.87, p=.0001, \eta^{2}=0.84\right)$.

This interaction effect reflected the fact that the difference between control condition $(M=0.06)$ and high dose condition $(\mathrm{M}=0.00)$ was greater in juveniles than adults.

\section{Velocity}

The main effect of the treatment was significant on the velocity in the open field, $F(2,30)=48.36, p=.0001, \eta^{2}$ $=0.76)$. The Tukey test indicated that the subject in the high dose condition ( $M=213.67)$ showed less velocity than those in the control condition $(\mathrm{M}=476.24)$ and those in the low dose condition $(M=467.86)$, with the last two being not significantly different from each other. The interaction effect between generation and treatment was also significant, $\left(F(2,30)=6.67, p=0.004, \eta^{2}=0.31\right)$.

This interaction reflected the fact that the difference between the control condition ( $M=536.91)$ and the high dose condition $(M=207.58)$ was greater in juveniles than the difference between control condition $(M=415.57)$ and high dose condition $(\mathrm{M}=219.77)$ in adults.

\section{ELEVATED MAZE MEASUREMENTS}

\section{Total distance travelled (TDT)}

The main effect of the generation was significant on the total distance travelled, $F(1,30)=18.36, p=0.0001, \eta^{2}$ $=0.38$. Adults $(M=1396.96)$ travelled more distance than juveniles $(M=941.05)$.

\section{Time spent in open arms (TSOA)}

The main effect of the treatment was significant on the time spent in open arms, $F(2,30)=4.24, p=0.02, \eta^{2}=$ 0.22 . The Tukey test indicated that the subject in the high dose condition ( $M=2.35 \mathrm{~min}$ ) spent more time in the open arms than those in the low dose condition $(M=1.38$ min) and those in the control condition $(M=1.59)$, with the last two being not significantly different from each other. The main effect of the generation was also significant on the time spent in open arms, $F(1,30)=$ 8.84, $p=0.006, \eta^{2}=0.23$. Adults $(M=2.22 \mathrm{~min})$ spent more time in the open arms than juveniles $(\mathrm{M}=1.35$ $\mathrm{min})$. In addition the interaction effect between generation and treatment was significant, $F(2,30)=7.59, p=0.002$, $\eta^{2}=0.34$. This interaction effect reflected the fact that the difference between control condition $(\mathrm{M}=1.35 \mathrm{~min})$ and high dose condition $(\mathrm{M}=3.51 \mathrm{~min})$ in time was greater in adults than the difference between the control $(\mathrm{M}=1.80$ $\mathrm{min})$ and the high dose condition $(M=1.20 \mathrm{~min})$ in juveniles.

\section{Entrance frequency to open arms (EFOA)}

No significant effects related to the treatment and generation and as well as the interaction effect between generation and treatment were found to be significant at $p>0.13$.

\section{Time spent in closed arms (TSCA)}

The main effect of the treatment was significant on the time spent in closed arms, $F(2,30)=4.17, p=0.03, \eta^{2}=$ 0.22 . The Tukey test indicated that the subject in the high dose condition ( $M=2.60 \mathrm{~min})$ spent less time in the closed arms than those in the low dose condition ( $\mathrm{M}=$ $3.60 \mathrm{~min})$ and those in the control condition $(M=3.38)$, with the last two being not significantly different from each other. The main effect of the generation was also significant on the time spent in closed arms, $F(1,30)=$ 8.70, $p=0.006, \eta^{2}=0.23$. Adults $(M=2.76 \mathrm{~min})$ spent less time in the closed arms than juveniles $(M=3.64$ min). In addition, the interaction effect between generation and treatment was significant $F(2,30)=7.67$, $p=0.002, \eta^{2}=0.34$. This interaction effect reflected the fact that the difference between control condition $(\mathrm{M}=$ $3.62 \mathrm{~min})$ and high dose condition $(\mathrm{M}=1.44 \mathrm{~min})$ in time was greater in adults than the difference between the control $(\mathrm{M}=3.14 \mathrm{~min})$ and the high dose condition $(\mathrm{M}=$ $3.78 \mathrm{~min}$ ) in juveniles.

\section{Entrance frequency to closed arms (EFCA)}

No significant effects related to the treatment and 
generation and as well as the interaction effect between generation and treatment were found to be significant at $p>0.23$.

\section{Mobility (MOB)}

The main effect of the generation was significant on the mobility, $F(1,30)=13.82, p=0.001, n^{2}=0.32$. Juveniles $(M=1.42)$ were more mobile than adults $(M=0.65)$.

\section{Velocity (VEL)}

The main effect of the treatment was significant on the velocity, $F(2,30)=15.82, p=0.0001, \eta^{2}=0.51$. The Tukey test indicated that the subjects in the high dose condition ( $M=270.47)$ were slower than those in the low dose condition $(\mathrm{M}=351.72)$ and those in the control condition ( $M=373.65)$, with the last two being not significantly different from each other.

\section{Rotation (ROT)}

The main effect of the treatment was significant on the rotation, $F(2,30)=5.11, p=0.01, \eta^{2}=0.25$. The Tukey test indicated that the subjects in the high dose condition $(M=3.50)$ rotated less frequently than those in the low dose condition $(\mathrm{M}=4.83)$ and those in the control condition $(M=6.17)$, with the last two being not significantly different from each other.

\section{Morris water maze measurements}

\section{Total distance travelled (TDT)}

The interaction effect between generation and treatment was significant on the total distance travelled, $F(2,28)=$ $3.70, p=.04, \eta^{2}=0.21$. This interaction reflected the fact that adults travelled more distance in high dose condition $(\mathrm{M}=908.33)$ than the control condition $(M=135.54)$, whereas juveniles travelled less distance in high dose condition ( $M=516.64)$ than the control condition $(M=$ 753.74).

\section{Time spent to find the platform (TSFP)}

The main effect of the treatment was significant on the time to find the platform on the Morris water maze, $F(2$, 28) $=6.81, p=0.04, \eta^{2}=0.33$. The Tukey test indicated that the subjects in the high dose condition ( $M=44.83 \mathrm{~s})$ spent more time to find the platform than those in the low dose condition ( $\mathrm{M}=10.37 \mathrm{~s})$ and those in the control condition $(\mathrm{M}=17.46)$.

\section{Time spent in the correct quadrant (TSCQ)}

The main effect of the treatment was significant on the time spent in the correct quadrant on the Morris Water maze, $F(2,28)=3.43, p=0.05, \eta^{2}=0.20$. The Tukey test indicated that the subjects in the high dose condition $(\mathrm{M}=0.17)$ spent more time in the correct quadrant than those in the low dose condition ( $\mathrm{M}=0.04 \mathrm{~s})$ and those in the control condition $(\mathrm{M}=0.076)$, with the last two being not significantly different from each other.

\section{The entrance frequency to the correct quadrant (EFCQ)}

The interaction effect between generation and treatment was significant on the entrance frequency to the correct quadrant, $F(2,28)=3.91, p=0.03, \eta^{2}=0.22$. This interaction reflected the fact that adults entered more frequently to correct quadrant in the high dose condition $(M=3.00)$ than the control condition $(M=1.00)$, whereas juveniles entered more frequently in the control condition $(\mathrm{M}=2.67)$ than the high dose condition $(\mathrm{M}=1.67)$.

\section{Mobility (MOB)}

The interaction effect between generation and treatment was significant on the mobility time, $F(2,28)=8.30, p=$ $0.001, \eta^{2}=0.37$. This interaction reflected the fact that adults were more mobile in the high dose condition $(M=$ $0.05)$ than the control condition $(\mathrm{M}=0.002)$, whereas juveniles were mobile in the control condition $(M=0.085)$ than the high dose condition ( $M=0.001)$.

\section{Velocity (VEL)}

The main effect of the treatment was significant on the velocity on the Morris Water maze, $F(2,28)=4.22, p=$ $0.03, \eta^{2}=0.23$. The Tukey test indicated that the subjects in the high dose condition $(M=1156.38)$ were slower than those in the low dose condition $(M=1482.68$ s) and those in the control condition $(M=1481.53)$, with the last two being not significantly different from each other. The interaction effect between generation and treatment was also significant, $F(2,28)=11.40, p=$ $0.0001, \eta^{2}=0.45$. This interaction reflected the fact that adults were faster in the high dose condition ( $\mathrm{M}=$ 1619.20) than the control condition $(M=1387.17)$, whereas juveniles were faster in the control condition (M $=1575.88)$ than the high dose condition $(M=693.56)$. 


\section{SUMMARY AND CONCLUDING REMARKS}

The results of the present study can be classified under two main headings: Anxiety-like behaviour (in open field apparatus and elevated plus maze) and spatial memory performance (in Morris water maze).

\section{Anxiety-like behaviours}

Motor functions such as spontaneous activity is measured by the open field. Open field test is also used to measure the anxiety like behavior in rodents (Benabid et al., 2008). The total distance traveled, the total number of entries to the center and the edge of the open field, the time spent in the center of the open field versus time spent at the edge of the open field and the mobility are frequently used parameters measured in open field test in the literature (Pyter and Nelson, 2006). In this maze, if the anxiety of the animal is high, the number of the entries to the edge of the open field is increasing and the total distance traveled is decreasing. The total number of the entries into the center and the edges provides a builtin control measure for general hyperactivity or sedation. In the present study it was found that in the open field, the subjects in the high doses of $B$. perennis administration; a) travelled less distance in open field, b) spent more time at the center of the open field, c) were less frequently to enter both the edge and the center of the open field, d) showed less mobility; and e) showed less velocity than those in the control and low dose of $B$. perennis administration. The elevated plus maze has been one of popular or widely used test to measure the anxiety like behaviours (Dawson and Tricklebank, 1995). In this maze, if the anxiety of the animal is high, the number of the entries to closed arms is increasing and the total distance traveled is decreasing. The total number of the entries into all arms provides a built-in control measure for general hyperactivity or sedation. Regarding elevated plus maze and open field tests, the present study represent a difference in mobility, which needs a further investigation. In the present study, it was found that in the elevated plus maze, the subjects in the high doses of $B$. perennis administration; a) spent more time in the open arms, b) spent less time in the closed arms, c) were less mobile d) were slower and e) rotated less frequently than those in the control and low dose of $B$. perennis administration.

Taken together, these results in both open field and elevated plus maze can be explained from the two perspectives: anxiolytic and anesthetic. With regard to anxiolytic perspective, $B$. perennis may inhibit the serotonergic activity via GABAergic system. B. perennis may act like 'benzodiazepines' which are widely used in reducing the anxiety-like behaviours. They make their effect by binding their receptors which are found near the GABA receptors and by making an allosteric effect. By this way they increase the affinity of these GABA receptors to benzodiazepines (Sinclair and Nutt, 2007). The anxiolytic effect of saponins (Jalsrai et al., 2010), essential oil (Bradley et al., 2007) and flavonoids (De Almedia et al., 2009) in different plants have been recently documented in the literature. B. perennis also includes these major constituents. The anxiolytic properties of the $B$. perennis may be attributed to these active components. Future studies should examine the exact mechanisms underlying the effects of $B$. perennis. With regard to anesthetic perspective, it may have a relevant effect via its anesthetic properties. In the present study, some parameters such as less distance travelled, less frequent entrance to the both edge and the center of the open field, less mobility and less velocity after $B$. perennis administration may suggest that it may also show an anesthetic effect. Regarding the generation, it was found that juveniles spent more time at the edge of the open field than adults. Adults spent more time at the center of the open field than juveniles. In the elevated plus maze, adults travelled more distance than juveniles. Adults spent more time in the open arms than juveniles. Adults also spent less time in the closed arms than juveniles. Taken together, these results suggest that, juveniles were more anxious than adults in both open field and elevated plus maze. There are the three plausible explanations for these outcomes. First, adult rats have more developed visual and olfactory sensations than juvenile rats. Secondly, prepubertal rats may be more anxious than postpubertal rats in searching for the environmental cues. There is some evidence indicating that anxiety impairs memory consolidation (Küçük et al., 2008; Schwabe and Wolf, 2010; Hawley et al., 2011). Thirdly, postpubertal rats may have more experiences than prepubertal rats in searching for environment. In the present study, we also found that, juveniles were more mobile than adults. This can be attributed to the fact that energy metabolism is higher in prepubertal rats than postpubertal rats. On the other hand, a high level of anxiety in juvenile may suppress the appearance of this metabolic energy and thereby decrease searching behavior.

In addition, the findings of the present research showed some interaction effects between treatment and generation. Specifically, it was found that in the open field, high dose of $B$. perennis (a) lead to travel less distance in juveniles than adults, (b) eliminated the difference between the juveniles and the adults in terms of time spent at the edge of open field, (c) increased the time spent at the center of the open field in adults, (d) decreased the mobility in juveniles more than adults. This means that the effect of $B$. perennis is more evident in juveniles than adults in open field. It was also found in the elevated plus maze, high dose of $B$. perennis, (a) leads to an increase in time spent in open arms in adults, (b) leads to a decrease in time spent in closed arms in adults. This means that the effect of $B$. perennis is more 
evident in adults than juveniles in elevated plus maze. This outcome can be due to the fact that a high energy metabolism in juveniles may sweep away the effects of $B$. perennis on anxiety whereas a relatively low energy metabolism in adults may be one of the best optimal condition for the emergency of $B$. perennis effect. One can see that, this effect was not consistent with what was found in open field and elevated plus maze. This difference may be due to the task difference between open field and elevated plus maze. The open field apparatus is testing the anxiety-like behaviour which may be encountered in an open area. The elevated plus maze is testing the height frightening. These aforementioned findings also suggest that the dose-dependent effect was stronger in adults than juveniles. Probably this indicates that these measures relate to more complex constructs than simple anxiety, since they are modulated differently by the generation factor. Regarding elevated plus maze and open field tests, the present study represent a difference between adults and juveniles, which needs a further investigation.

\section{Spatial memory performance}

Morris water maze is one of the most suitable tests for the investigation of spatial memory (Hooge and De Deyn, 2001). In this test, the animal is trying to find a hidden platform which is found below the water level by using some cues around the experimental area. The time passed to find the platform, the time spent in correct quadrant, and the entrance frequencies to the correct and the other quadrants are used as the parameters representing the spatial memory and learning performance of the animals. Since our focus was on spatial memory, we used the Morris water maze test. In the present study it was found that in the Morris water maze, the subjects in the high doses of $B$. perennis administration; a) increased the distance travelled in adults, b) increased the time to find the platform, c) increased the time spent in correct quadrant, d) increased the the number of the entries to the correct quadrant in adults, e) decrease the mobility in general but increase the mobility in adults. Regarding the time spent to find the platform and the distance travelled, we assume that the high dose of $B$. perennis decreases the learning performance. On the other hand, such dose leads to an increase in time spent in the correct quadrant. This outcome indicates the beneficial effect of $B$. perennis on spatial memory. Taken together, these outcomes can be explained via the anxiolytic and the anesthetic properties of $B$. perennis. In other words, the anxiolytic effects of $B$. perennis may produce facilitatory effect on searching the platform in the correct quadrant. Besides, high dose of $B$. perennis may also produce anesthetic effect which in term may increase the time to find the platform and the distance travelled indicating decrement in the learning performance. The effects of
$B$. perennis on spatial learning performances in water maze have also been explained from its active ingredients. The amelioriation effect of flavonoids (Spencer, 2009, 2010) and essential oil (Zhang et al., 2007) on memory in different plants have been recently documented in the literature. On the other hand, its active ingredient namely saponins were reported to have detrimental effect on learning in mice (Lee et al., 2010).

In the present study, the increase in distance travelled and time spent to find the platform may be under the effects of saponins. On the other hand, the increase in the time spent in correct quadrant after the administration of $B$. perennis may be determined by both flavonoids and essential oil. In conclusion, B. perennis may produce biphasic or bipolar effects (that is, both beneficial and detrimental effects) on learning performance. Future studies should examine the exact mechanisms underlying the effects of $B$. perennis on learning and memory.

\section{REFERENCES}

Avato P, Vitali C, Mongelli P, Tava A (1997). "Antimicrobial activity of polyacetylenes from Bellis perennis and their synthetic derivatives, Planta. Med., 63: 503-507.

Baytop T (1999). Therapy with Medicinal Plants in Turkey (Past and Present)", 2nd edition. Nobel Medical Bookhouse, Istanbul, p. 371

Benabid N, Mesfioui A, Ouichou A (2008). Effects of photoperiod regimen on emotional behaviour in two tests for anxiolytic activity in Wistar rat", Brain. Res. Bull., 75: 53-59.

Bown D (1995). Encyclopaedia of Herbs and Their Uses", Dorling Kindersley, London, p. 141

Bradley F, Starkey NJ, Brown SL, Lea RW (2007). The effects of inhalation of essential oil odour from Rosa damascene Mill. On gerbils in two models of anxiety", Planta. Med., 73: 984.

Davis PH (1975). Flora of Turkey and the East Aegean Islands", 5. Edinburgh University Press, Edinburgh, p. 135.

Dawson GR, Trickklebank MD (1995). Use of the elevated plu-maze in the search for novel anxiolytic agents". Trends Pharmalogical. Sci., 16: 33-36.

De Almeida ER, Rafael KRD, Couto GBL, Ishigami ABM (2009). Anxiolytic and Anticonvulsant effects on Mice of Flavonoids, Linalool, and alpha-Tocopherol Presents in the Extract of Leaves of Cissus sicyoides L. (Vitaceae)", J. Biomed. Biotechnol., 1: 6.

Desevedavy C, Amoros M, Girre L (1989). Antifungal agents. In vitro and in vivo antifungal extract from the common daisy, Bellis perennis", J. Nat. Prod., 52: 184-185.

Duke JA, Bogenschutz-Godwin MJ, DuCellier J, Duke PA (2002). Handbook of Medicinal Plants". 2nd. Ed. CRC Press, Boca Raton, FL, p. 273.

Grieve M (1982). A Modern Herbal", Dover Publications, Inc., New York, I, p. 247.

Gudej J, Nazaruk J (2001). Flavonol glycosides from the flowers of Bellis perennis, Fitoterapia, 72: 839-840.

Hawley WR, Grissom EM, Dohanich GP (2011). The relationships between trait anxiety, place recognition memory, and learning strategy", Behavioural. Brain Res., 216: 525-530.

Hiller K, Schopke T, Wray V, Schulten HR (1988). The structure of the major saponins from Bellis perennis L. Pharmazie., 43: 850-852.

Hooge RD, De Deyn PP (2001). Applications of the Morris water maze in the study of learning and memory", Brain Res. Rev., 36: 60-90.

Jalsrai A, Grecksch G, Becker A (2010). Evaluation of the effects of Astragalus mongholicus Bunge saponin extract on central nervous system functions". J. Ethnopharmacol., 131: 544-549.

Kavalcioglu N, Acik L, Demirci F, Demirci B, Demir H, Baser KHC (2010). Biological activities of Bellis perennis volatiles and extracts", 
Nat. Prod. Commun., 5: 147-150.

Kucuk A, Golgeli A, Saraymen R, Koc N (2008). Effects of age and anxiety on learning and memory", Behavioural Brain Res., 195: 147152.

Lee B, Jung K, Kim DH (2010). Timosaponin Alll, a saponin isolated from Anemarrhena asphodeloides, ameliorates learning and memory deficits in mice". Pharmacol. Biochem. Behav., 93: 121-127.

Li W, Asada Y, Koike K, Nikaido T, Furuya T, Yoshikawa T (2005). Bellisosides A-F, six novel acylated triterpenoid saponins from Bellis perennis (compositae)". Tetrahedron., 61: 2921-2929.

Morikawa T, Li X, Nishida E, Ito Y, Matsuda H, Nakamura S, Muraoka O, Yoshikawa M (2008). Perennisosides I-VII, Acylated Triterpene Saponins with Antihyperlipidemic Activities from the Flowers of Bellis perennis. J. Nat. Prod., 71(5): 828-835.

Morikawa T, Li X, Nishida E, Nakamura S, Ninomiya K, Matsuda H, Oda Y, Muraoka O, Yoshikawa M (2010b). Medicinal Flowers Part 29 Acylated Oleanane-Type Triterpene Bisdesmosides: Perennisaponins G, H I, J, K, L, and M with Pancreatic Lipase Inhibitory Activity from the Flowers of Bellis perennis", Helvetica Chimica Acta., 93 (3): 573-586.

Morikawa T, Muraoka O, Yoshikawa M (2010a). Pharmaceutical Food Science: Search for Anti-obese Constituents from Medicinal FoodsAnti-hyperlipidemic Saponin Constituents from the Flowers of Bellis perennis", Yakugaku Zasshi. J. Pharm. Soc. Japan., 130 (5): 673678.

Oberbaum M, Galoyan N, Lerner-Geva L, Singer SR, Grisaru S. Shashar D, Samueloff A (2005). The effect of the homeopathic remedies Arnica montana and Bellis perennis on mild postpartum bleeding- A randomized, double-blind, placebo- controlled studyPreliminary results". Complementary Therapies in Medicine, 13(2): 87-90.

Panda H (2004). Handbook on Medicinal Herbs with Uses", Asia Pacific Business Press, India, pp. 188-189.

Pyter LM, Nelson RJ (2006). Enduring effects of photoperiod on affective behaviors in Siberian hamsters (Phodopus sungorus)", Behavioral Neurosci., 120: 125-134.
Regional Health Forum: WHO South- East Asia Region (Volume 5, Number 1) Agenda for the Mental Health Programme in South-East Asia.

Schopke T, Wray V, Kunath A, Hiller K (1990). Virgaureasaponin-2 from Bellis perennis L.", Pharmazie, 45: 870-871.

Schopke T, Wray V, Rzazewska B, Hiller K (1991). Bellissaponin-BA1 and Bellissaponin-BA2 - Acylated Saponins from Bellis perennis", Phytochemitry, 30: 627-631.

Schopke T, Wray V, Kunath A, Hiller K (1992). Bayogenin and asterogenic acid glicosides from Bellis perennis", Phytochemistry, 31: 2555-2557.

Schwabe L, Wolf OT (2010). Stress impairs the reconsolidation of autobiographical memories", Neurobiol. Learn. Memory, 94: 153157.

Sinclair L, Nutt D (2007). Anxiolytics”, Psychiatry, 6(7): 284-288.

Spencer JPE (2009). Flavonoids and brain health: multiple effects underpinned by common Mechanisms". Genes. Nut., 4(4): 243-250.

Spencer JPE (2010). The impacts of fruit flavonoids on memory and cognition", British. J. Nut., 104: 40-47.

Tutin TG, Heywood VH, Burges NA, Moore DM, Valentine DH, Walters SM, Webb DA (1976). Flora Europaea", Volume 4, Cambridge. Great Britain: Cambridge University Press. p. 111.

Yoshikawa M, Li X, Nishida E, Nakamura S, Matsuda H, Muraoka O, Morikawa T (2008). Medicinal Flowers. XXI. Structures of Perennisaponins A, B, C, D, E, and F, Acylated Oleanane-Type Triterpene Oligoglycosides, from the Flowers of Bellis perennis", Chem. Pharm. Bull., 56: 559-568.

Zhang H, Han T, Yu CH, Rahman K, Qin LP, Peng C (2007). Ameliorating effects of essential oil from Acori graminei rhizoma on learning and memory in aged rats and mice, J. Pharm. Pharmacol., 59: 301-309. 